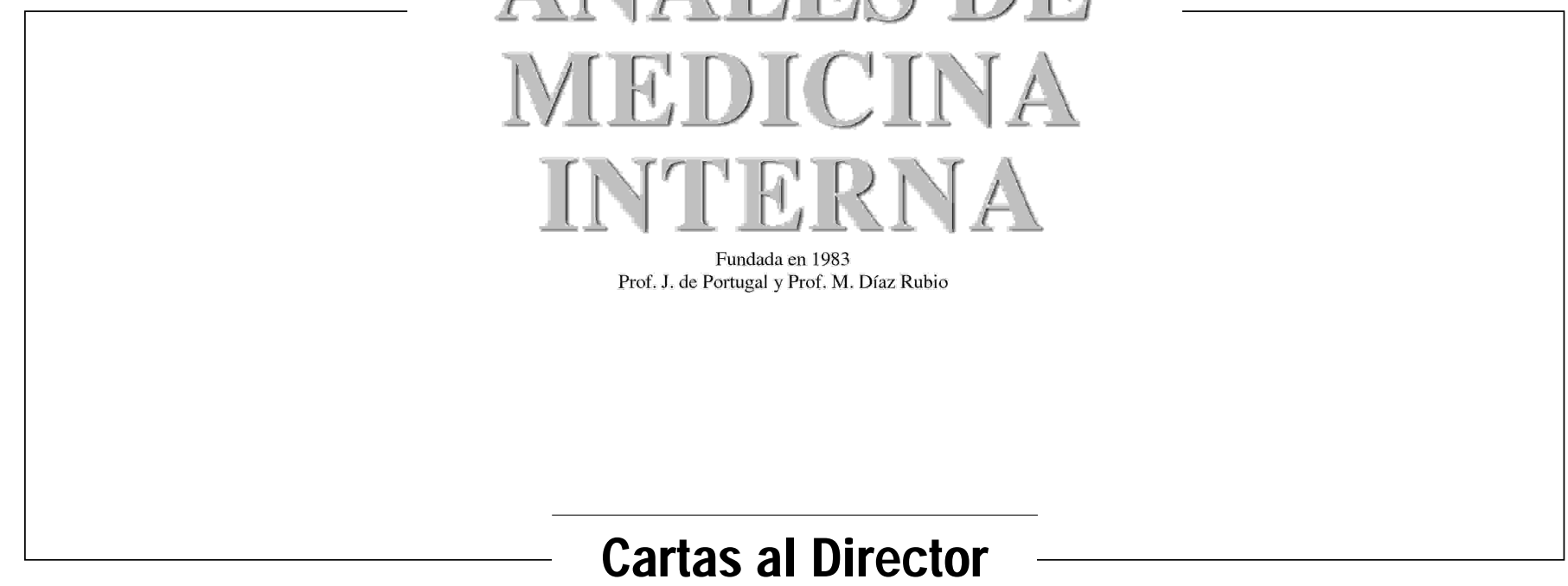

\section{Metástasis gástrica de carcinoma de pulmón}

\section{Sr. Director:}

El cáncer de pulmón de células pequeñas, supone el $25 \%$ de todos los cánceres de pulmón. Las localizaciones metastásicas más habituales son las cerebrales, hepáticas y en las glándulas suprarrenales no obstante, también pueden ocasionalmente aparecer metástasis en otros lugares del organismo, como puede ser el estómago. A continuación presentamos un paciente que es ingresado por síntomas digestivos, y en el que se diagnosticó un cáncer de pulmón con localización secundaria en estómago.

Varón de 52 años de edad, cuyo único antecedente de interés era ser fumador de dos paquetes al día desde hacía unos 30 años. Consulta en Urgencias por dolor epigástrico que irradia en cinturón a espalda de una semana de duración, más intenso por la noche y que progresivamente ha aumentado en intensidad. En la exploración física el enfermo presentaba caquexia con atrofia muscular importante y no se palpaban adenopatías periféricas. A la auscultación pulmonar se apreciaba hipoventilación a nivel del lóbulo inferior del pulmón izquierdo. El abdomen era doloroso de forma difusa a la palpación, destacando una hepatomegalia dolorosa de $4 \mathrm{~cm}$. En la radiografía de tórax destacaba una condensación de bordes irregulares a nivel del lóbulo inferior del pulmón izquierdo. Se realiza ecografía abdominal en urgencias y se aprecian metástasis hepáticas múltiples y líquido libre intraabdominal. Analíticamente destacaba una hemoglobina de $11 \mathrm{~g} / \mathrm{dl}$, hematocrito de $31,7 \%$, plaquetas 64,3 x $10^{9}$, leucocitos $5,46 \times 10^{9}$, velocidad de sedimentación de 80 $\mathrm{mm} / \mathrm{h}$, bilirrubina total $4,5 \mathrm{mg} / \mathrm{dl} \quad(0,1-1,1), \quad$ LDH 1192 U/L(230-460), Gamma GT 341 U/L(11-50), Fosfatasa Alcalina 797 U/L(98-258), GOT 148 (5-37), GPT 103 U/L (5-40), amilasa pancreática 879 U/L(8-53) y lipasa 936 U/L (10-190). Se realiza gastroscopia en la que se aprecian nódulos submucosos redondeados en número de tres sobre la cara posterior del cuerpo gástrico, umbilicados en su centro y con un centímetro de diámetro que se biopsian, el estudio anatomopatológico de estos nódulos sugería metástasis de carcinoma de células pequeñas (Fig. 1). La TAC torácico abdominal demostró la existencia de una tumoración a nivel del pulmón izquierdo y un hígado metastásico. Se realizó una broncoscópia donde se visualiza la lesión a nivel del bronquio lobar superior izquierdo, realizándose aspirado y cepillado bronquial con biopsia de la lesión, todas ellas compatibles con carcinoma indiferenciado de células pequeñas de pulmón. En los cinco días que el enfermo estuvo

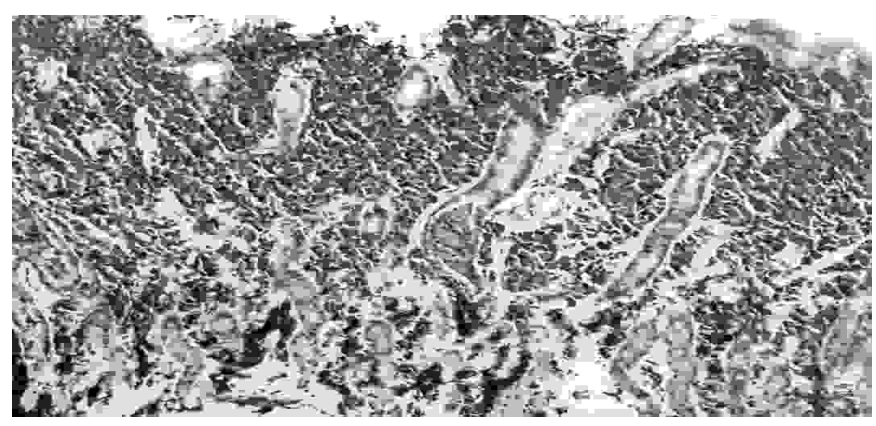

Fig. 1. La mucosa gástrica muestra una ocupación de la lámina propia por células pequeñas e hipercromáticas, sin apenas citoplasma que respetan gran parte del epitelio glandular.

ingresado, sufrió un deterioro progresivo del estado general, presentando un cuadro de coagulación intravascular diseminado. Se decidió no efectuar más pruebas diagnosticas, siendo únicamente tributario de medidas paliativas falleciendo al sexto día del ingreso.

En series post-mortem se ha evidenciado que la incidencia de metástasis gastrointestinales en pacientes con enfermedades neoplásicas oscila entre el 1-4\% dependiendo de diferentes estudios (1). Las lesiones primarias más frecuentes en la producción de metástasis gástricas son el carcinoma broncogénico de pulmón, el melanoma y el carcinoma de mama. Aproximadamente entre un 2-9\% de los carcinomas de pulmón metastatizan en el tubo digestivo (50\% intestino delgado, $30 \%$ intestino grueso, 20\% estómago), según las distintas series necropsicas. El carcinoma de pulmón de células pequeñas primario tiene tendencia a progresar rápidamente y metastatizar de una forma precoz, sobre todo a nivel del hígado, hueso, glándulas adrenales y sistema nervioso central. En algunos casos se han evidenciado metástasis gástricas, la mayoría de ellas en autopsias, algunos autores han recogido el porcentaje de metástasis gástricas, con una frecuencia del $2 \%$ de todas las autopsias de pacientes fallecidos con carcinoma de pulmón de células pequeñas. Las metástasis gástricas son frecuentemente asintomáticas (90\%), al contrario que las óseas y pulmonares. La sintomatología, cuando existe, es inespecífica, presentando anorexia, náuseas, vómitos, epigastralgia, hemorragia gastrointestinal y disfágia, aunque algunos autores mencionan el sangrado como 
síntoma mayoritario. A partir de la existencia de afectación gástrica los pacientes fallecen en un período de tiempo de uno a dos meses, contribuyendo a ello la anorexia y la hemorragia. Radiológicamente estas lesiones submucosas son responsables de la típica imagen en "ojo de buey". La imagen endoscópica es la de un tumor submucoso, generalmente una o varias lesiones circunscritas en el interior de la pared gástrica, pueden presentar una depresión o ulceración central. En algunas ocasiones la biopsia es negativa, ya que la mucosa no suele estar afectada y son necesarias biopsias profundas para realizar el diagnostico anatomopatológico. En la actualidad se está utilizando la ecoendoscopia como método altamente sensible para localizar lesiones parietales. Las lesiones se localizan en las capas submucosa y muscular, mientras que la mucosa y serosa no suelen estar afectadas, esto sugiere que la diseminación se produce por vía hematógena. Las metástasis gástricas de carcinomas extraintestinales suelen ser un estado final en la progresión de la enfermedad, el tratamiento debe ser paliativo ya que no se ha demostrado un aumento de la supervivencia con cirugía, radioterapia o quimioterapia. El pronostico es sombrío con una supervivencia de menos de un mes desde la aparición de los síntomas.

R. Baños Madrid, J.J. Martínez Crespo, S. Morán Sánchez, A. Albaladejo Meroño, A. Serrano Jiménez, J. Mercader Martínez

Servicio de Aparato Digestivo. Hospital Universitario Virgen de la Arrixaca. Murcia

1. Telerman A, Gerard B, Van den Heule B, Bleiberg H. Gastrointestinal metastases from extraabdominal tumors. Endoscopy 1985; 17: 99-101.

2. Maeda J, Miyake M, Tokita K, Iwahashi N, Nakano T, Tamura S, et al. Small cell lung cancer with extensive cutaneus and gastric metastases. Internal Med 1992; 31 (11): 1325-8.

3. Alba MA, Piedrafita E, Chivite de León A, Allende L, Sáinz S. Metástasis gástrica de carcinoma de mama. Rev Esp Enf Digest 1997; 89 (8): 647-9.

4. Asch MJ, Wiedel PD, Habif DV. Gastrointestinal metastases from carcinoma of the breast. Arch Surg 1968; 96: 840-843.

5. Hartmann WH, Sherlock P. Gastroduodenal metastases from carcinoma of the breast. Cancer 1961; 14 (2): 231-46. 